\title{
Hemiballism-hemichorea Induced by Subcortical Ischemia
}

\author{
Toshiya Fukui, Yukihiro Hasegawa, Shinya Seriyama, Toru Takeuchi, \\ Koujiro Sugita and Hiroshi Tsukagoshi
}

\begin{abstract}
Four patients presented with hemiballism-hemichorea as a clinical manifestation of white matter ischemia. These patients illustrate "positive" motor phenomena rather than limb weakness as a consequence of cerebral ischemia. In each patient, the involuntary movements disappeared following worsening of paresis. Subcortical white matter infarction in three patients and hemodynamic hypo-perfusion in the cerebral hemisphere contralateral to dyskinetic movements were possible causes. Neuroradiologically, none had pathological changes in the vicinity of the subthalamic nucleus. We presume from these observations that ischemia of the subcortical white matter, without involvement of the basal ganglia or the subthalamic nucleus, may cause hemiballism-hemichorea.
\end{abstract}

RÉSUMÉ: Hémiballisme-hémichorée induite par ischémie sous-corticale: à propos de quatre cas. Quatre patients se sont présentés avec hémiballisme-hémichorée comme manifestation clinique d'une ischémie de la substance blanche. Ces cas soulèvent une question intéressante mais peu explorée, à savoir l'apparition de phénomènes moteurs positifs plutôt que d'une faiblesse comme conséquence d'une ischémie cérébrale. Les mouvements involontaires sont disparus chez tous les patients suite à une aggravation de la parésie. Un infarctus de la substance blanche sous-corticale en était possiblement la cause chez trois patients, alors que chez l'autre le phénomène était possiblement dû à une hypo-perfusion hémodynamique de l'hémisphère cérébral contra-latéral. Au point de vue neuroradiologique, aucun ne manifestait de changements pathologiques dans le voisinage du noyau sous-thalamique. Ces observations nous portent à croire qu'une ischémie de la substance blanche sous-corticale contralatérale, sans atteinte du noyau lenticulaire, du noyau caudé, de l'avant-mur, du noyau amydalien ou du noyau sous-thalamique, peut causer l'hémiballisme-hémichorée.

Can. J. Neurol. Sci. 1993; 20: 324-328

Ballistic or choreic dyskinesia, or both, on one side of the body (hemiballism-hemichorea) is a clinical entity caused mainly by vascular lesions in the subthalamic nucleus ${ }^{1-9}$ or other structures. ${ }^{3.69-15}$ There have been few clinical reports of cortical or subcortical white matter lesions associated with involuntary movements. ${ }^{10,16}$

We report four patients who had involuntary movements of relatively short duration and concomitant paresis of the same $\operatorname{limb}(\mathrm{s})$. We speculate that subcortical ischemia was a primary cause of these symptoms. We also discuss a possible mechanism of these "positive" motor phenomena occurring after white matter lesions.

\section{Case Reports}

\section{Patient I}

An 82-year-old hypertensive woman suddenly experienced paresthesia of pins and needles in the left arm and the same limb started involuntarily to "hop and jump" an hour later. The dyskinesia consisted of sporadically appearing hovering and flinging movements of the entire left upper limb intermingled with rotation, flexion-extension or pronation-supination of the arm and hand. The face and legs were not involved. These movements were resistant to intravenous administration of glycerol, phenobarbital, diazepam and phenytoin, although sleep induced by the hypnotizing effect of some of these medications was effective in reducing the severity of the movements. The patient was otherwise intact neurologically except for reduced muscle tone in the left extremities.

The dyskinesia continued unchanged for 22 hours. As a slowly evolving monoparesis of the left arm became apparent, it decreased in frequency and amplitude and finally disappeared 24 hours after onset. Weakness of the left upper extremity improved in three days without recurrence of the involuntary movements.

Electroencephalography (EEG) was normal without epileptic discharge. CT 20 hours after the onset of the abnormal movements was unremarkable. A CT on day 4 disclosed an indistinct low density in the subcortical white matter of the precentral and premotor cortex on the right side, representing a fresh cerebral infarct (Figure la). The thalamus, basal ganglia and subthalamus appeared undamaged and there was no other lesion detected on CT (Figure lb). MRI and angiography were not obtainable.

\section{Patient 2}

A 75-year-old hypertensive man noticed a sudden tingling numbness of the left half of the body, followed shortly after by flailing involuntary movements of the left extremities. On admission the same day, we observed the following dyskinesia superimposed on mild left hemiparesis:

From the Department of Neurology, Showa University School of Medicine, Tokyo (T.F., Y.H., S.S., T.T., K.S.), and Kakeyu Hospital, Nagano (H.T.), Japan Received November 3, 1992. Accepted in final form May 19, 1993

Reprint requests to: Toshiya Fukui, M.D., Department of Neurology, Showa University School of Medicine, 1 - 5 - 8 Hatanodai, Shinagawa - ku, Tokyo, 142 Japan 


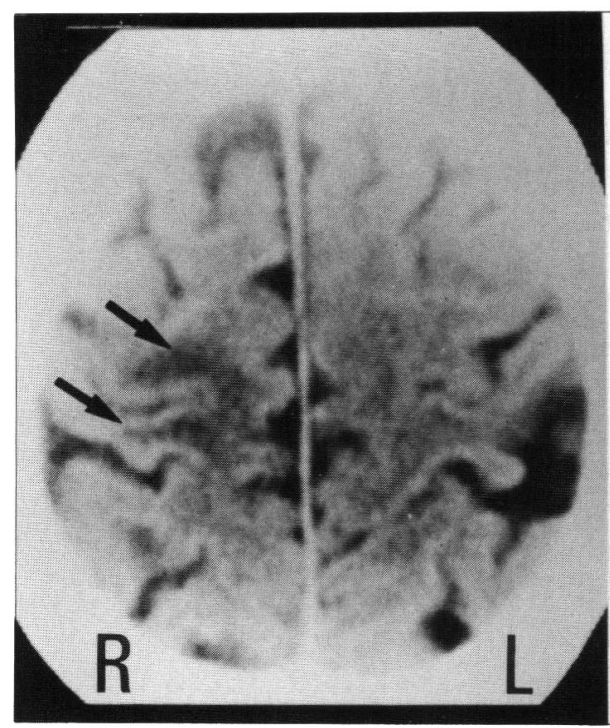

A

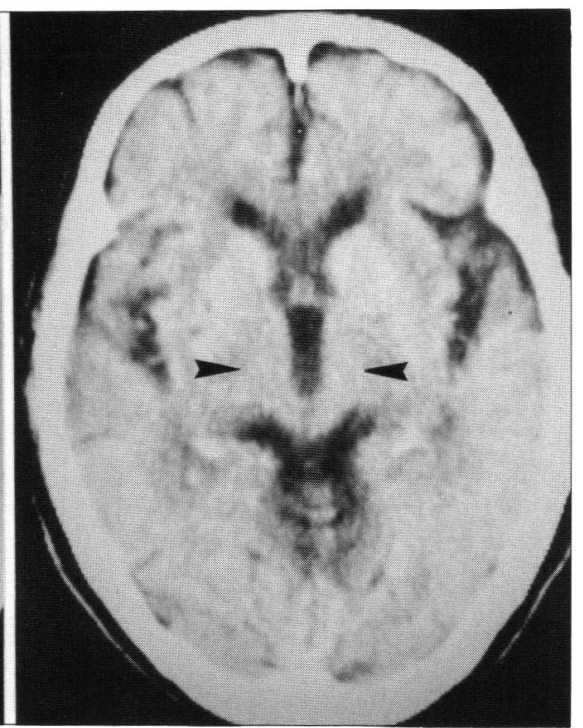

B
Figure I - (Patient I):(A) Plain CT scan show's a fresh infarction confined to the white matter of the precentral and premotor cortices on the right side (arrow's). (B) The basal ganglia and the subthalamic areas (arrow heads) appear intact. the whole left arm swung irregularly and sporadically with large excursions around the shoulder joint, coupled with non-synchronous swift rotations of the forearm and flexion-extension at the elbow and wrist joints. In addition, complex movements of the left leg appeared, consisting of irregular and non-repetitive abduction-adduction, flexionextension and inversion-eversion at the hip, knee and ankle joints. Repetitive intramuscular administrations of phenobarbital and diazepam failed to control these movements. Two and a half hours after onset, the dyskinetic movements slowly subsided until they completely resolved as the paresis of the left extremities gradually worsened. The left hemiparesis resolved in 10 days without recurrence of abnormal movements.

EEG was normal. CT performed 6 hours after the onset revealed a reduced density at the right fronto-parietal subcortical white matter and centrum semiovale, which was more clearly depicted on the follow-up CT (Figure 2a) on day 8 . On brain MRI on day 19, the corresponding region appeared high-signaled on a T2-weighted image (T2WI) without involving the overlying cortex, basal ganglia or subthalamic nucleus (Figure 2b, c). Angiography revealed subtotal occlusion of both internal carotid arteries at the cervical bifurcations. Single photon emission computed lomography (SPECT) using ${ }^{49 \mathrm{~m} T \mathrm{Tc}}$ hexamethyl-propyleneamine oxime (HM-PAO) on day 11 showed hypoperfusion at the right frontal convexity and the centrum semiovale corresponding to the ischemic lesion on CT and MRI.

\section{Patient 3}

An 86-year-old woman was hospitalized because of a sudden rightsided weakness. Subsequently, the following dyskinesia was observed: the entire right arm was sporadically and violently rotated in an inversive-eversive fashion at the shoulder joint with the elbow slightly flexed. These movements lasted for a few minutes, then were substituted by dyskinesia of the right leg: coarse and irregular extension-flexion at the hip and knee joints which lasted another few minutes. The involuntary movements of the right extremities continued for an hour and gradually subsided after aggravation of right hemiparesis.

EEG was normal except for a small amount of theta waves in the left centro-parietal region. A plain CT examined 3 hours after the onset and MRI on day 35 showed a subcortical white matter infarction of the left centrum semiovale (Figure $3 a, b$ ). The subthalamic nucleus appeared uninjured on MRI (Figure 3c). A SPECT using $\mathrm{N}$-isopropyl123]-iodoamphetamine (IMP) on day 7 revealed an uptake reduction at the left fronto-parietal region. Angiography was not performed.

\section{Patient 4}

A 59-year-old man had continuous, but slight involuntary movements of sudden onset in his left extremities. A few days later, he experienced several episodes of left-sided transient weakness with a duration of a few minutes followed by complete recovery. He incidentally noticed that the dyskinesia would disappear transiently during paresis and reappear thereafter. Along with a series of similar episodes, the involuntary movements became more violent, and he was admitted to our hospital six days after the onset of symptoms. He had mild left facial weakness and reduced muscle tone in the left limbs. The dyskinesia on the left side consisted of: swift grimacing, pouting and shruging; flinging and rotatory movements of the whole arm and leg; and a mixture of flexion-extension, abduction-adduction and inversion-eversion at each joint. These movements, in various combinations, appeared sporadically or occasionally in bursts. Although there was no recurrence of paresis after the patient was placed on ticlopidine, the dyskinesias persisted with reduced amplitude and frequency.

EEG was normal. On brain MRI on day 31 , a frontal and possible occipital lesions in the left contrum semiovale were depicted as highsignaled spots on T2W1 and no abnormality was detected in the right hemisphere (Figure 4a). The subthalamic nuclei seemed intact (Figure 4b). HM-PAO SPECT on day 7 suggested hypo-perfusion, although slight, in the right parietal as well as in the left fronto-parietal regions (Figure 4c). Tracer uptake appeared normal in the basal ganglia and subthalamic areas. The patient refused angiography.

\section{Discussion}

Ballism is characterized by regular flinging movements with proximal predominance, ${ }^{9}$ and chorea by irregular, non-repetitive, and quasi-purposeful movements with distal predominance. ${ }^{17}$ They often occur simultaneously on one side of the body, hence the name hemiballism-hemichorea. ${ }^{3.10 .18 \cdot 20}$ There is a tendency for the left side to be more frequently affected. ${ }^{7.21}$

Hemiballism may be a pathognomonic feature of destructive lesions, usually of vascular origin, of the contralateral subthalamic nucleus. ${ }^{1.2,4-6.9}$ Hemiballism-hemichorea can also occur with a small vascular lesion of the basal ganglia, ${ }^{12}$ lenticular nucleus, ${ }^{14}$ or the caudate nucleus, ${ }^{11.13 .15}$ which have been confirmed at 


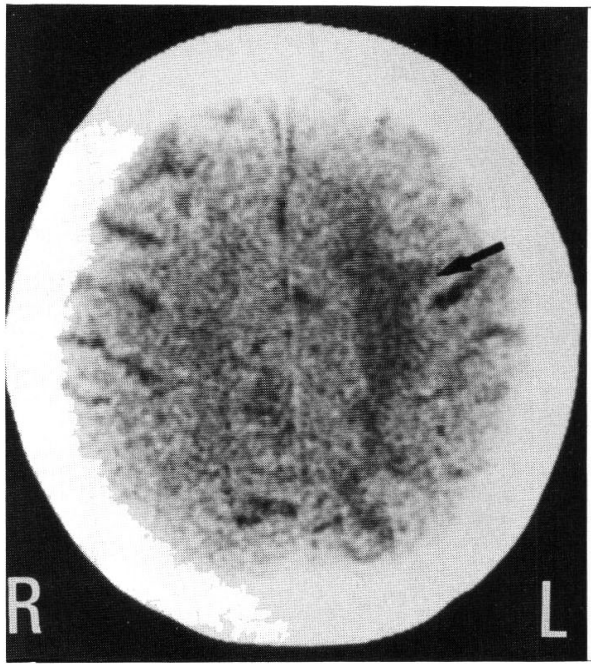

A

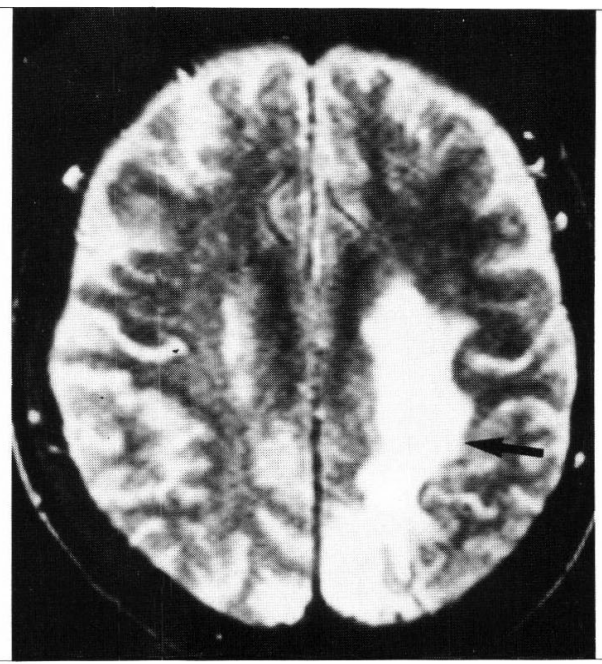

B

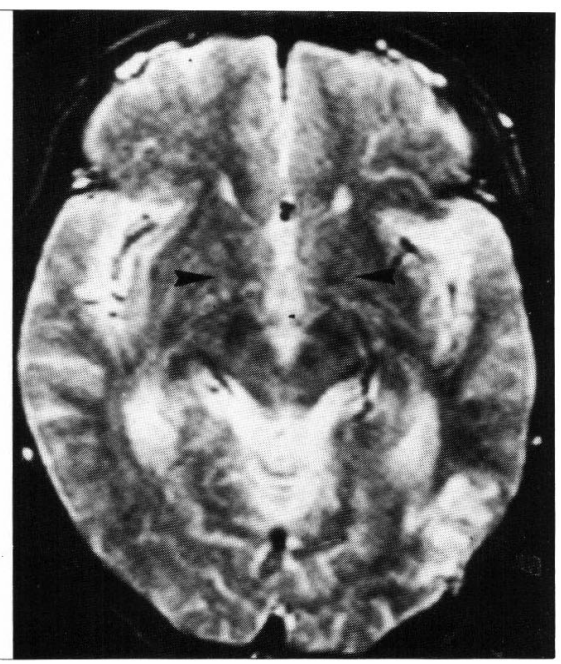

C

Figure 2-(Patien 2): (A) Plain CT shows an extensive low density area in the right centrum semiovale (arrow). (B) which appears high-signaled (arrow) on T2-weighted image (TR $3.000 \mathrm{msec}$, TE $100 \mathrm{msec}$ ) on MRI (Toshiba MRT-50A, 0.5 tesla). (C) The subthalamic regions (arrow' heads) appear intact on MRI.

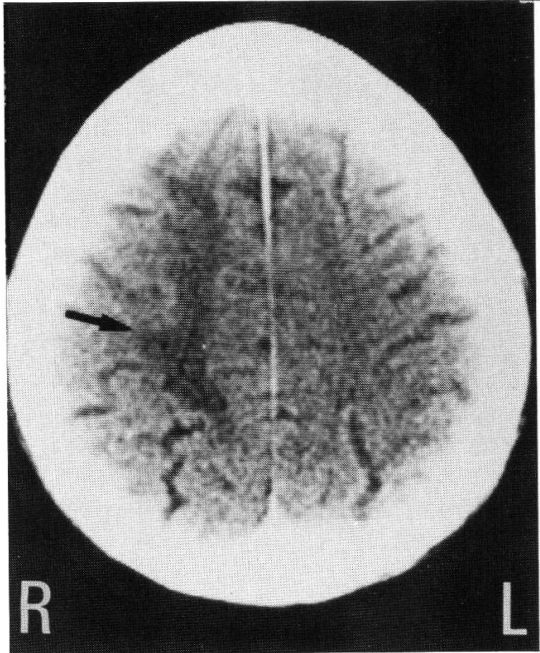

A

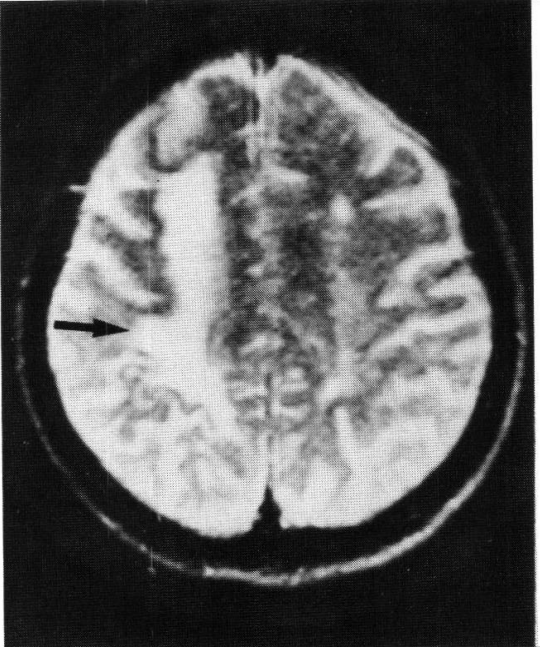

B

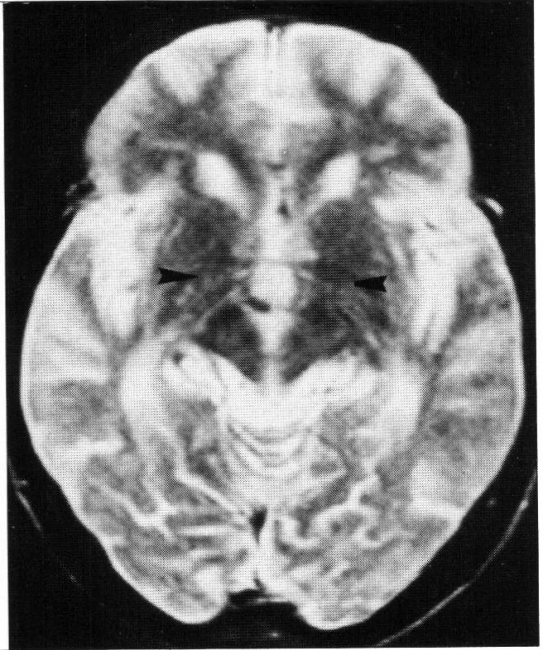

C

Figure 3-(Patient 3): Plain CT (A) and MRI (B) show a diffuse subcortical infarction in the left centrum semiovale (arrows), which may antedate the episode of acute stroke. The subthalamic regions (arrow heads in (C) appear normal.)

autopsy ${ }^{3,10,11}$ or on CT. ${ }^{12-15}$ A cortical or subcortical lesion is an extremely rare cause of non-epileptic dyskinetic disorders and includes infarction at the superior frontal and precentral gyri, ${ }^{10}$ or nonspecific atrophy of the postcentral gyrus ${ }^{16}$ contralateral to dyskinesia.
In patient $\mathbf{1}$, although a CT examination alone may be inadequate to exclude the possibility of subthalamic involvement, we considered that a newly appearing subcortical white matter infarct of the right precentral gyrus was responsible both for involuntary movements and monoparesis of the left arm. In 


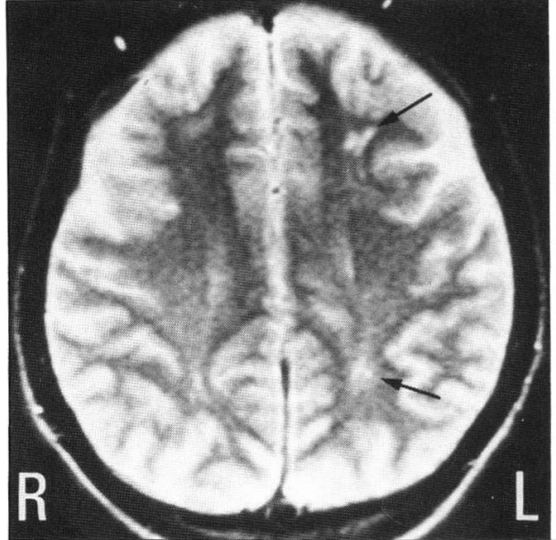

A

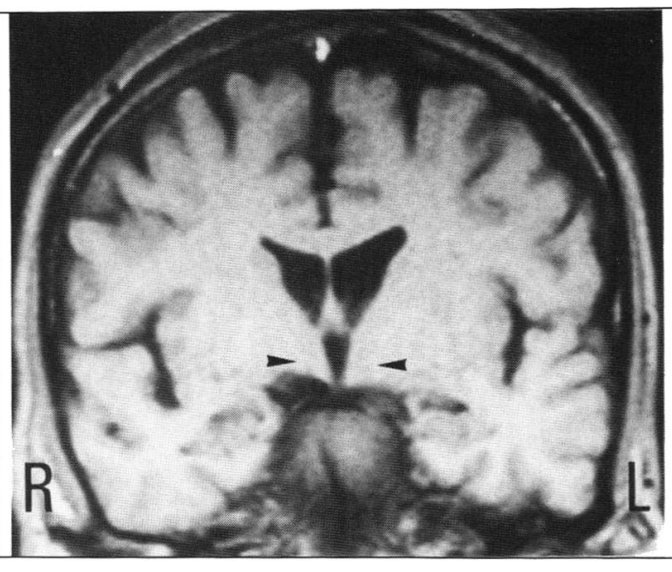

B

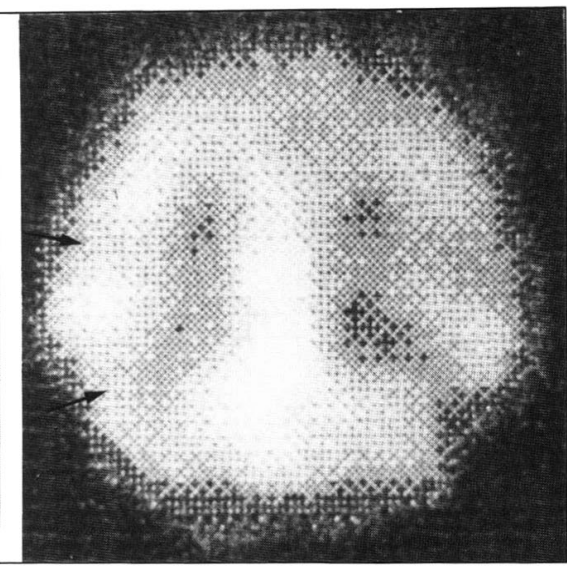

C

Figure 4-(Patient 4): (A) Besides some white matter lesions in the left centrum semiovale (arron's), no specific lesion can be identified in the right hemisphere on T2-weighted (TR $2.500 \mathrm{msec}$, TE $100 \mathrm{msec}$ ) MRI scan. (B) The subthalamic regions (arrow heads) appear normal on T/-w'eighted (TR $300 \mathrm{msec}, T E 14 \mathrm{msec)}$ coronal scan (C) HM-PAO SPECT shows that tracer uptake is reduced slightly in the right parietal region (arrows) and more extensively in the left hemisphere.

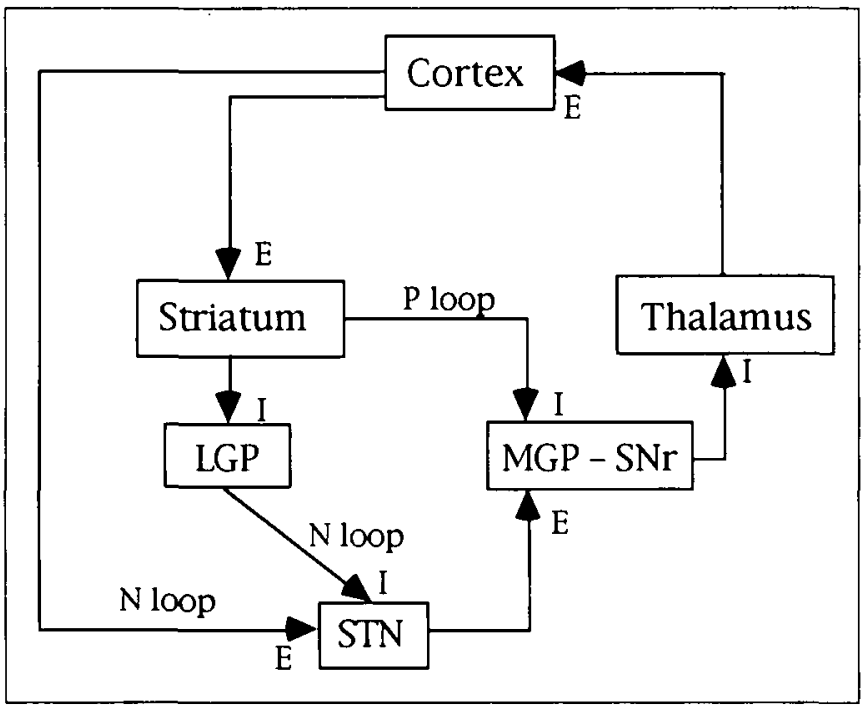

Figure 5 - Schematic model of positive and negative feedhack loops for motor excution. Abbreviations are: LGP, lateral globus pallidus: MGP, medial globus pallidus: SNr; substantia nigra reticulata: STN, subthalamic nucleus; E. excitatory neural projection; I. inhibitory neural projection; $P$, loop positive feedback loop; $N$, loop negative feedback loop.

patients 2 and 3 , diffuse white matter infarcts contralateral to hemiballism-hemichorea may have caused an acute onset of hemiparesis as well as involuntary movements, although the imaged infarct might have existed prior to the recent stroke in patient 2 . In patient 4 , we could not identify any specific lesion in the right hemisphere but speculated from the SPECT that hypo-perfusion in the right hemisphere, which may be a result of a steal phenomenon caused by the more ischemic left hemisphere, was responsible for transient hemiparesis and dyskinesia. Angiography would be needed in this patient to clarify the etiology further.
In patients 2, 3 and 4, as in patient 1, transient ischemia or minute pathological changes in the subthalamic nucleus, which would escape MRI detection, cannot be excluded totally from the possible etiologies of hemiballism-hemichorea. However, the probability that such undetected lesions exist is low since they are unlikely to produce concomitant paresis.

Differential diagnoses include Huntington's chorea, chorea acanthocytosis, senile chorea, or dyskinesias of metabolic and toxic etiologies. ${ }^{9.17}$ However, the acute clinical course and unilateral involvement in our patients indicated a vascular origin. Post-apoplectic partial seizure may be differentiated by lack of compatible EEG abnormalities.

Normal motor sequences are controlled by complex positive and negative feedback circuits (Figure 5). ${ }^{22-25}$ In essence, the precentral and prefrontal cortices send excitatory projections to the corpus striatum. For the promotion of ongoing movements, the striatum inhibits the medial globus pallidus (MGP) and substantia nigra reticulata ( $\mathrm{SNr}$ ), which, as a consequence, disinhibit the thalamus and cortex (positive feedback loop). For inhibition of undesirable movements, the striatum suppresses the lateral globus pallidus and inhibitory projections to the subthalamic nucleus, which exerts excitatory action on the MGP and SNr. These latter structures then inhibit the thalamus and cortex ${ }^{24.25}$ (negative feedback loop). An alternative excitatory pathway which projects from the precentral motor cortex directly to the subthalamic nucleus has been identified. ${ }^{26}$

According to this theory, selective disruption of the negative feedback loop would result in "disinhibition" of the motor cortex and occurrence of involuntary movements. It is possible that hemiballism-hemichorea occurs when a lesion is situated anywhere in this loop, whether it is in the basal ganglia, subthalamic nucleus, or subcortical white matter. When more of the motor cortex or the pyramidal tract is involved, motor paresis may eliminate any dyskinesia.

Although subcortical white matter infarction is common, resultant hemiballism-hemichorea is only rarely encountered, probably because selective disruption of the negative loop may seldom occur, or because most lesions may cause paresis, precluding involuntary dyskinesia. 


\section{REFERENCES}

1. Martin JP. Hemichorea resulting from a local lesion of the brain. Brain 1927; 50: 637-651.

2. Moersch FP, Kernohan JW. Hemiballismus. A clinicopathologic study. Arch Neurol Psychiatry 1939; 41: 365-372. (Correction 41; 1939: 1276.)

3. Papez JW, Bennett AE, Cash PT. Hemichorea (hemiballismus). Association with a pallidal lesion, involving afferent and efferent connections of the subthalamic nucleus; curare therapy. Arch Neurol Psychiatry 1942; 47: 667-676.

4. Whittier JR. Ballism and the subthalamic nucleus. (Nucleus hypothalamicus; corpus Luysi). Review of the literature and study of thirty cases. Arch Neurol Psychiatry 1947; 58: 672-692.

5. Meyers R, Sweeney DB, Schwidde JT. Hemiballismus: etiology and surgical treatment. J Neurol Neurosurg Psychiatry 1950; 13 : 115-126.

6. Meyers R. Ballismus I $n$ : Vinken PJ, Bruyn GW, eds. Diseases of the basal ganglia. Handbook of Clinical Neurology, vol 6 . Amsterdam: North-Holland, 1968; 476-490.

7. Winfield ME. Transient hemiballism. Ann Intern Med 1960; 53: 822-827.

8. Melamed E, Korn-Lubetzki 1, Reches A, Siew F. Hemiballismus: detection of focal hemorrhage in the subthalamic nucleus by $\mathrm{CT}$ scan. Ann Neurol 1978; 4: 582.

9. Burama OJS, Lakke JPWF. Ballism. In: Vinken PJ, Bruyn GW, Klawans HL, eds. Extrapyramidal disorders. Handbook of Clinical Neurolgy, vol 49. Amsterdam: Elsevier, 1986; 369-380.

10. Martin JP. Heimichorea (hemiballismus) without lesions in the corpus Luysii. Brain 1957; 80:1-12.

11. Schwarz GA, Barrows LJ. Hemiballism without involvement of Luys' body. Arch Neurol 1960; 2: 420-434.

12. Kase CS, Maulsby GO, deJuan E, Mohr JP. Hemichorea-hemiballism and lacunar infarction in the basal ganglia. Neurology 1981; 31: $452-455$.
13. Saris S. Chorea caused by caudate infarction. Arch Neurol 1983; 40: $590-591$.

14. Mas JL, Launay M, Derouesne C. Hemiballism and CT-documented lacunar infarct in the lenticular nucleus. J Neurol Neurosurg Psychiatry 1987; 50: 104-105.

15. Ikeda $M$, Tsukagoshi $H$. Monochorea caused by a striatal lesion. Eur Neurol 1991; 31: 257-258.

16. Wilson SAK. Die Pathogenese der unwillkurlichen Bewegungen mit besonderer Berucksichtigung der Pathologie und Pathogenese der Chorea. Dtsch Z Nervenheilkd 1929; 108: 4-38.

17. Martin JP. Choreatic syndromes. In: Vinken PJ, Bruyn GW, eds. Diseases of the Basal Ganglia. Handbook of Clinical Neurology, vol 6. Amsterdam: North-Holland, 1968: 435-439.

18. Johnson WG, Fahn S. Treatment of hemiballism and hemichorea. Neurology 1977; 27: 634-636.

19. Crossman AR, Sambrook MA, Jackson A. Experimental hemichorea/hemiballismus in the monkey. Brain 1984; 107: 579-596.

20. Lownie SP, Gilbert JJ. Hemichorea and hemiballismus: recent concepts. Clin Neuropathol 1990; 9: 46-50.

21. Carpenter MB, Mettler FA. Analysis of subthalamic hyperkinesia in the monkey with special reference to ablation of agranular cortex. J Comp Neurol 1951; 95: 125-157.

22. Penney JB, Young AB. Speculations on the functional anatomy of basal ganglia disorders. Ann Rev Neurosci 1983; 6: 73-94.

23. Young AB, Penney JB. Neurochemical anatomy of movement disorders. Neurol Clin 1984; $2: 417-433$.

24. Penney JB, Young AB. Striatal inhomogeneities and basal ganglia function. Mov Disord 1986; 1: 3-15.

25. Albin R, Young A, Penney J. The functional anatomy of basal ganglia disorders. Trends Neurosci 1989; 12: 366-375.

26. Hartmann-van Monakow K, Akert K, Kunzle H. Projections of the precentral motor cortex and other cortical areas of the frontal lobe to the subthalamic nucleus in the monkey. Exp Brain Res $1978 ; 33: 395-403$. 